\title{
Prediksi Tekanan Pori Menggunakan Metode Kompresibilitas di Reservoir Karbonat, Studi Kasus : Lapangan MZ
}

\author{
Muhazzib F, Ayi Syaeful Bahri, dan Amien Widodo \\ Departemen Teknik Geofisika, Fakultas Teknik Sipil dan Perencanaan, Institut Teknologi Sepuluh Nopember (ITS) \\ e-mail: syaeful_b@geofisika.its.ac.id
}

\begin{abstract}
Abstrak-Prediksi tekanan pori sangat diperlukan pada aktifitas eksplorasi hingga pengembangan lapangan minyak dan gas bumi. Prediksi yang akurat dapat menentukan berat jenis lumpur pemboran yang tepat sehingga menjadikan aktifitas pemboran sumur di industri minyak dan gas bumi lebih efektif, aman, dan efisien. Penelitian bertujuan untuk menghitung tekanan pori di reservoir karbonat menggunakan metode kompresibilitas dan membandingkan hasil perhitungan dengan data tekanan langsung (RFT), d'exponent, permasalahan pemboran dan tekanan lumpur, lalu menganalisa mekanisme yang menyebabkan overpressure pada lapangan penelitian, dan menentukan rekomendasi berat jenis lumpur pemboran untuk sumur MZ. Parameter kompresibilitas yaitu kompresibilitas bulk dan pori didapatkan melalui proses fluid replacement modelling (FRM) menggunakan persamaan Gassmann. Penyebab overpressure di analisis berdasarkan karakteristik data log shale terhadap kurva normal compaction trend (NCT) dan menunjukkan bahwa overpressure pada lapangan penelitian disebabkan oleh mekanisme loading akibat laju sedimentasi yang tinggi pada formasi Ngrayong. Selain itu, parameter kompresibilitas yang di hitung melalui proses FRM bernilai $5,9 \times 10^{-7}-8,1 \times 10^{-7}$ untuk kompresibilitas pori dan $1,4 \times 10^{-7}-2,3 \times 10^{-7}$ untuk kompresibilitas bulk. Nilai tersebut bertujuan sebagai input pada metode kompresibilitas dan menghasilkan nilai hasil perhitungan tekanan pori yang cukup baik, ditunjukkan oleh kecocokan dengan nilai tekanan lumpur dan permasalahan pemboran, serta selisih rata-rata antara nilai perhitungan tekanan pori dengan data RFT yang kurang dari 500 psi, yaitu 162.63 psi.
\end{abstract}

Kata Kunci-Kompresibilitas Bulk, Kompresibilitas Pori, Reservoir Karbonat, Tekanan Pori

\section{PENDAHULUAN}

$\mathrm{E}_{\mathrm{p}}^{\mathrm{s}}$ STIMASI tekanan pori dengan akurat sangat diperlukan pada seluruh aspek eksplorasi dan pengembangan minyak dan gas bumi [1]. Prediksi tekanan pori merupakan analisis fundamental yang digunakan untuk berbagai tujuan, seperti : penentuan batuan induk yang telah matang, penentuan migrasi fluida, penentuan struktur dan patahan, hingga evaluasi integrasi batuan tudung suatu cekungan [2]. Selain itu, memprediksi tekanan pori juga sangat berguna pada proses pemboran, yaitu untuk menentukan berat jenis lumpur agar dapat memastikan proses pemboran berjalan dengan aman [3]. Tekanan pori berdasarkan nilainya dibagi menjadi 2 jenis, yaitu tekanan normal (hidrostatik) dan tekanan abnormal (overpressure dan under pressure). Tekanan overpressure dapat mengakibatkan berbagai permasalahan yang dapat menganggu proses pemboran seperti pipe stuck, kick, hingga blowout [4].

Metode perhitungan tekanan pori untuk litologi karbonat berbeda dengan litologi shale. Hal tersebut disebabkan oleh heterogenitas dari batuan karbonat. Metode kompresibilitas mengadopsi dua parameter heterogenitas reservoir karbonat, yaitu kompresibilitas bulk dan kompresibilitas pori [5]. Metode tersebut telah digunakan oleh beberapa penelitian sebelumnya, seperti reservoir karbonat di Iran [5] dan di lapangan gas Iran Selatan [4] Berdasarkan penelitian tersebut, metode kompresibilitas dapat memprediksi tekanan pori di reservoir karbonat dengan baik. Selain itu, pada kedua penelitian tersebut, parameter kompresibilitas bulk dan pori didapatkan dari data core dan persamaan empiris antara porositas dan kompresibilitas. Namun, pada penelitian ini parameter tersebut didapatkan dari proses fluid replacement modelling.

Penelitian studi ini tidak hanya bertujuan untuk mendapatkan nilai kompresibilitas bulk dan kompresibilitas pori yang dihitung menggunakan data well log melalui proses FRM, tetapi juga mengetahui mekanisme yang menyebabkan overpressure di wilayah penelitian, lalu memprediksi tekanan pori di reservoir karbonat menggunakan metode kompresibilitas. Nilai tekanan pori di reservoir karbonat hasil perhitungan akan dibandingkan dengan tekanan lumpur pemboran pada sumur penelitian berdasarkan data aktual mudweight, data tekanan langsung (RFT), serta perhitungan d'exponent. Selain itu, penelitian juga bertujuan untuk menentukan berat jenis lumpur pemboran yang aman dan efisien pada reservoir karbonat di Lapangan MZ.

\section{DASAR TEORI}

\section{A. Konsep Tekanan Bawah Permukaan Bumi}

Tekanan yang berada di bawah permukaan bumi terdiri atas beberapa jenis. Tekanan tersebut secara langsung mempengaruhi aktifitas pemboran hingga produksi minyak dan gas bumi. Konsep dasar dari jenis tekanan bawah permukaan bumi dijelaskan melalui persamaan Terzaghi yaitu sebagai berikut :

$$
S=P_{p}+\sigma_{e f f}
$$


Dimana :

$P_{p}=$ Tekanan pori (psi)

$\mathrm{S} \quad=$ Tekanan overburden (psi)

$\sigma_{\text {eff }}=$ Tekanan efektif (psi)

Persamaan (1) menunjukkan bahwa terdapat tiga jenis tekanan bawah permukaan bumi. Yang pertama adalah tekanan overburden yang merupakan tekanan pada kedalaman tertentu yang diakibatkan oleh beban sedimen di atasnya [6]. Yang kedua adalah tekanan pori yang merupakan tekanan yang disebabkan oleh fluida yang berada di dalam pori-pori batuan sedimen atau batuan lainnya [3]. Yang ketiga adalah tekanan efektif yang merupakan tekanan yang diakibatkan oleh jarak antar butir suatu batuan [7]. Menurut (1), tekanan overburden akan ditanggung bersama-sama oleh tekanan pori dan tekanan efektif. Terdapat dua jenis tekanan pori, yaitu tekanan overpressure dan tekanan underpressure. Tekanan overpressure merupakan tekanan pori yang bernilai melebihi tekanan hidrostatik, sedangkan tekanan underpressure adalah tekanan pori yang bernilai kurang dari tekanan hidrostatik. Selain itu, juga terdapat tekanan rekah atau fracture pressure. Tekanan rekah merupakan total dari tekanan yang dapat ditahan oleh formasi sebelum suatu formasi tersebut rusak atau hancur. Nilai dari tekanan rekah harus lebih kecil dari tekanan overburden dan lebih besar dari tekanan pori. Besarnya gradien tekanan rekah umumnya dipengaruhi oleh : tekanan overburden, tekanan formasi dan kondisi kekuatan batuan [7].

\section{B. Mekanisme Terjadinya Overpressure}

Tekanan overpressure dengan magnitudo yang besar diakibatkan oleh 2 mekanisme, yaitu akibat pembebanan (loading) dan non-pembebanan (unloading) [7].

1) Mekanisme Pembebanan (Loading). Proses pengendapan sedimen akan meningkatkan tekanan vertikal atau pembebanan sedimen secara gravitasi. Proses tersebut berpotensi menyebabkan tekanan overpressure akibat ketidakseimbangan kompaksi atau disequilibrium compaction. Pada proses tersebut, tekanan overpressure disebabkan oleh kompetisi yang terjadi antara kecepatan fluida untuk keluar dari sistem dan kecepatan kompaksi secara vertikal akibat peningkatan pembebanan gravitasi dari proses sedimentasi. Jika laju pengendapan lebih tinggi dibandingkan dengan kecepatan fluida keluar dari sistem maka akan menyebabkan batuan yang gagal untuk terkompaksi. Mekanisme pembebanan umumnya terjadi pada zona transisi dari lingkungan yang dominan batupasir ke lingkungan dominan shale [6].

2) Mekanisme Non-Pembebanan (Unloading). Proses ini dapat menyebabkan tekanan overpressure yang tinggi melalui proses yang memindahkan kontak antar butir ke fluida pori. Proses konversi dari material matriks padat menjadi fluida akan secara otomatis meningkatkan tekanan pori, jika fluida pori tidak bisa keluar dari sistem. Jika beban butir batuan tertransformasi menjadi fluida, maka beberapa tekanan yang sebelumnya dihasilkan dari kontak antar butir akan berubah menjadi fluida, lalu menghasilkan peningkatan tekanan pori. Terdapat beberapa kondisi geologi yang menyebabkan mekanisme unloading, seperti proses transformasi smektit - illit pada pembentukan mineral clay, pembentukan hidrokarbon, dan perpindahan secara lateral maupun vertikal [9].

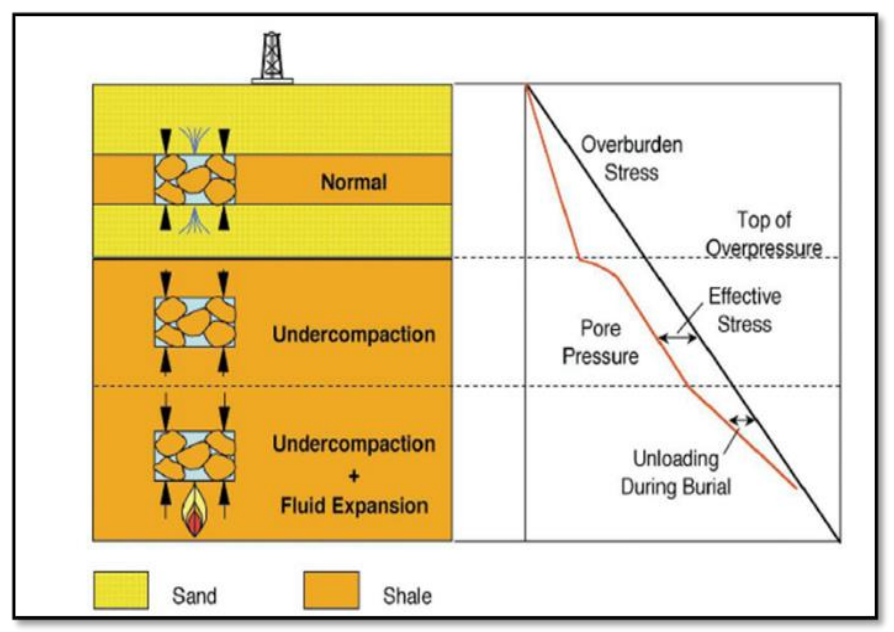

Gambar 1. Respon tekanan efektif terhadap nilai tekanan pori berdasarkan jenis penyebab overpressure. Pada mekanisme loading, nilai tekanan efektif akan paralel dengan tekanan pori, sedangkan pada mekanisme unloading, nilai tekanan efektif semakin berkurang, atau nilai tekanan pori semakin mendekati nilai tekanan overburden.

\section{Metode Kompresibilitas}

Metode kompresibilitas merupakan metode yang menggunakan properti reservoir yaitu kompresibilitas batuan untuk menghitung tekanan pori. Metode ini didasari pada perbedaan karakteristik dari batuan shale dan batuan karbonat, sehingga metode yang sebelumnya telah ada hanya valid digunakan untuk litologi shale. Metode ini dikembangkan oleh [5] yang menganalisis bahwa tekanan pori bergantung pada perubahan volume pori, sehingga jika terdapat perubahan jarak pori merupakan fungsi dari batuan dan kompresibilitas fluida. Secara umum, ketika formasi berada pada tekanan, jarak pori akan berkurang dan menyebabkan terjadinya overpressure pada tekanan fluida. Berikut adalah persamaan yang digunakan pada metode kompresibilitas :

$$
P_{p}=\left(\frac{(1-\phi) \times C_{b} \times \sigma_{e f f}}{(1-\phi) \times C_{b}-\left(\phi \times C_{p}\right)}\right)^{\gamma}
$$

Dimana :

$\phi=$ Porositas (dec)

$C_{b}=$ Kompresibilitas bulk

$C_{p}=$ Kompresibilitas pori

$\Upsilon=$ Konstanta empiris

\section{METODOLOGI}

\section{A. Analisa Log}

Analisa $\log$ bertujuan untuk mengetahui posisi batas atas dan batas bawah dari target penelitian, yaitu reservoir karbonat. Analisa menggunakan karakteristik dari respon masing-masing data log, crossplot gamma ray dengan $p$ impedance, dan analisa data mudlog. Pada metode analisa 
karakteristik respon $\log$ terhadap litologi, data $\log$ yang digunakan adalah log gamma ray (GR), sonik, resistivitas, dan porositas. Sedangkan pada metode crossplot, reservoir karbonat ditunjukkan oleh nilai gamma ray yang rendah dan nilai impedansi yang tinggi. Berikut adalah hasil dari analisa log pada sumur MZ :

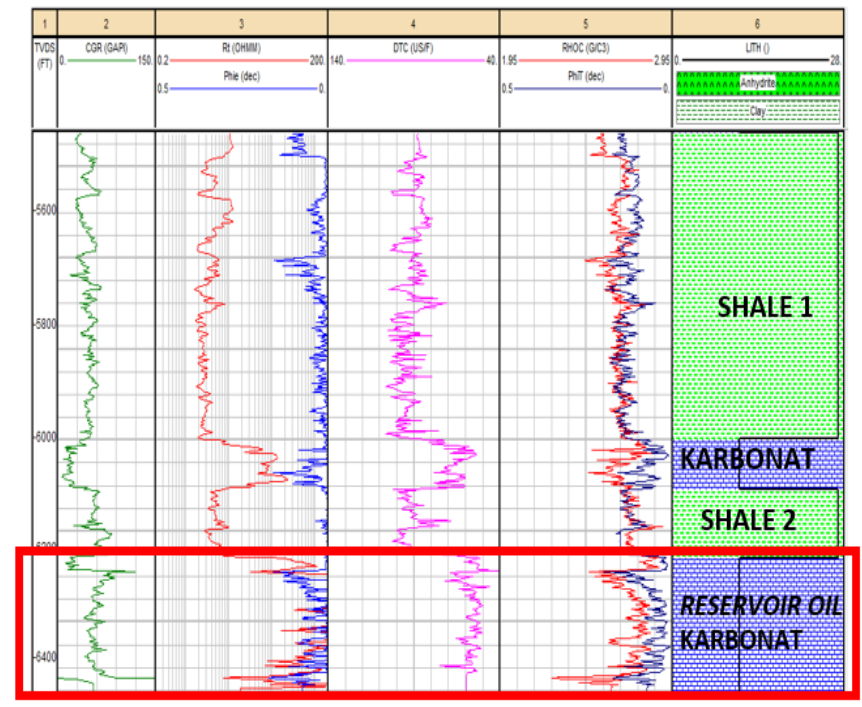

Gambar 2. Hasil analisa log pada sumur MZ. Reservoir karbonat terletak mulai $6221.76 \mathrm{ft}$ hingga $6468.28 \mathrm{ft}$ dengan jenis oil reservoir. Reservoir tersebut merupakan bagian dari reservoir karbonat formasi Tuban

\section{B. Perhitungan d'Exponent}

Metode d'Exponent bertujuan untuk menghilangkan efek variasi parameter pemboran agar mendapatkan nilai yang hanya dipengaruhi oleh litologi dan tekanan. Terdapat beberapa parameter pemboran yang digunakan untuk melakukan perhitungan d'Exponent seperti : kecepatan pemboran, rotation speed, ukuran mata bor, hingga berat jenis lumpur yang digunakan [6]. Persamaan yang digunakan untuk menghitung d'Exponent adalah sebagai berikut :

$$
d=\frac{\log _{10} \frac{R}{60 \times N}}{\log _{10} \frac{12 \times W}{10^{6} \times D}} \times \frac{\rho_{\text {normal }}}{\rho_{\text {lumpur }}}
$$

Dimana :

$\mathrm{R}=$ Kecepatan pemboran

$\mathrm{N}=$ Rotasi per menit

$\mathrm{W}=$ Weight on bit

$\mathrm{D}=$ Ukuran mata bor

\section{Perhitungan Tekanan Overburden}

Data yang digunakan untuk menghitung tekanan overburden adalah log densitas. Tekanan overburden dihitung mulai dari kedalaman dangkal hingga kedalaman akhir dari pengukuran log densitas. Namun, pengukuran log densitas pada umumnya dimulai dari zona interest sehingga menyebabkan data log densitas untuk kedalaman dangkal tidak tersedia. Oleh karena itu, dibutuhkan perhitungan nilai densitas untuk kedalaman dangkal atau kedalaman yang tidak dijangkau oleh pengukuran logging densitas. Penelitian ini menggunakan persamaan densitas Miller untuk menghitung nilai densitas dangkal, yaitu sebagai berikut :

$$
\rho_{s}=\rho_{m} \times\left(1-\phi_{s}\right)+\rho_{m} \times \phi_{s}
$$

Dimana :

$\rho_{s}=$ Densitas dangkal Miller (gr/cc)

$\rho_{m}=$ Densitas matriks batuan solid (gr/cc)

$\phi_{s}=$ Porositas kedalaman dangkal (frac)

Nilai porositas pada kedalaman dangkal $\left(\phi_{s}\right)$ dihitung dengan menggunakan persamaan :

$$
\phi_{s}=\left(\phi_{a}+\phi_{b}\right) e^{-k \times d \times \frac{1}{N}}
$$

Dimana $\phi_{a}$ dan $\phi_{b}$ merupakan porositas sedimen (frac), serta nilai $\mathrm{k}$, d, dan $\mathrm{N}$ merupakan parameter konstanta Miller. Setelah itu, nilai tekanan overburden dihitung dengan menggunakan persamaan berikut :

$$
S_{n}=S_{n-1}+\left(\rho_{b} \times h \times 0.433\right)
$$

\section{Perhitungan Tekanan Hidrostatik}

Parameter yang mempengaruhi nilai tekanan hidrostatik adalah densitas dari fluida formasi. Pada penelitian ini, densitas fluida yang digunakan adalah densitas fresh water yaitu sebesar $1 \mathrm{gr} / \mathrm{cc}$. Persamaan yang digunakan untuk menghitung tekanan hidrostatik adalah sebagai berikut :

$P_{h}=0.433 \times h$

0.433 merupakan gradien satuan imperial untuk densitas fluida $1 \mathrm{gr} / \mathrm{cc}$.

\section{E. Perhitungan Tekanan Pori}

Sebelum menghitung tekanan pori menggunakan metode kompresibilitas, terlebih dahulu dilakukan perhitungan terhadap parameter kompresibilitas bulk dan kompresibilitas pori. Kedua parameter tersebut dihitung melalui fluid replacement modelling menggunakan persamaan Gassman, dengan langkah sebagai berikut : 


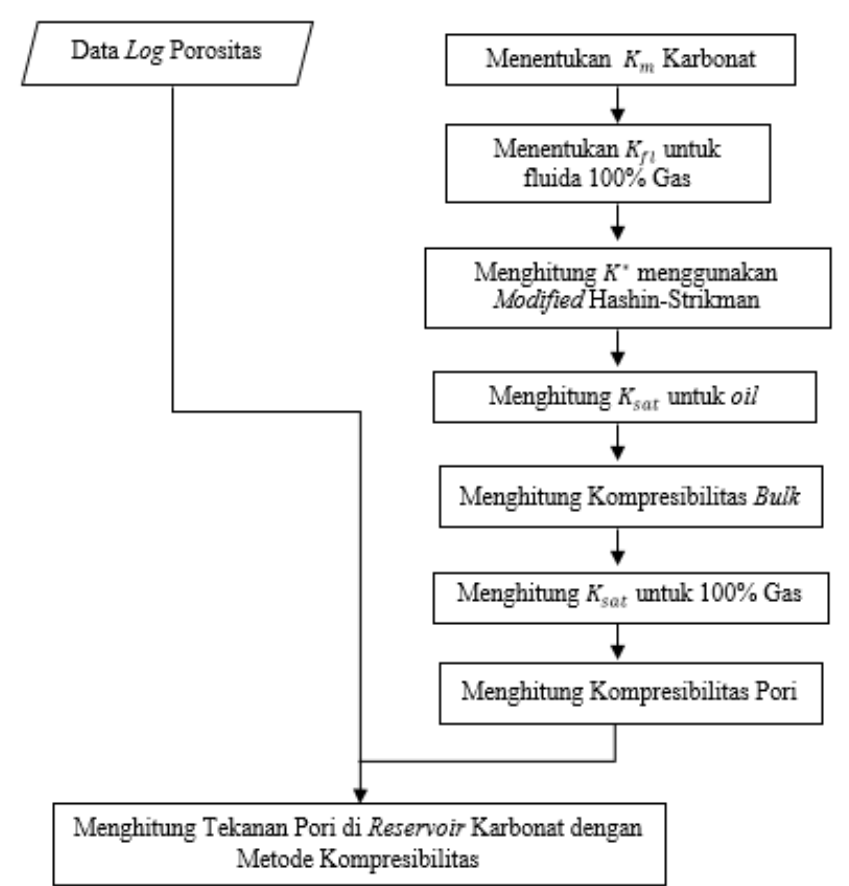

Gambar 3. Proses perhitungan tekanan pori di reservoir karbonat menggunakan metode kompresibilitas. Proses FRM dilakukan dengan mengganti fluida reservoir menjadi $100 \%$ gas agar mendapatkan nilai kompresibilitas yang maksimum.

\section{F. Perhitungan Tekanan Rekah}

Tekanan rekah bertujuan sebagai salah satu parameter pada proses penentuan berat jenis lumpur pemboran. Hal tersebut dikarenakan nilai berat jenis lumpur pemboran harus kurang dari nilai tekanan rekah sebagai nilai yang menunjukkan batasan dari kekuatan suatu batuan. Persamaan yang digunakan untuk menghitung tekanan rekah yaitu sebagai berikut :

$$
\sigma_{\min }=\frac{\vartheta}{1-\vartheta}\left(S-P_{p}\right)+P_{p}
$$

Dimana :

$$
\begin{aligned}
& \sigma_{\min }=\text { Tekanan rekah (psi) } \\
& \vartheta \quad=\text { Poisson ratio }
\end{aligned}
$$

\section{HASIL DAN PEMBAHASAN}

\section{A. Analisa Penyebab Overpressure Lapangan $M Z$}

Penyebab overpressure dapat diketahui melalui karakteristik shale yang ditunjukkan melalui data wireline logging terhadap normal compaction trend (NCT). NCT adalah grafik yang menunjukkan berkurangnya porositas shale seiring dengan bertambahnya kedalaman atau dengan kata lain proses kompaksi shale secara normal. Perubahan nilai log shale terhadap kurva NCT menunjukkan zona yang memiliki tekanan overpressure. Selain itu, perubahan tren nilai tersebut juga menunjukkan karakteristik penyebab overpressure, yaitu mekanisme loading dan mekanisme unloading [7]. Perbedaan antara kedua mekanisme tersebut yaitu :

\section{Loading in homogeneous shale}

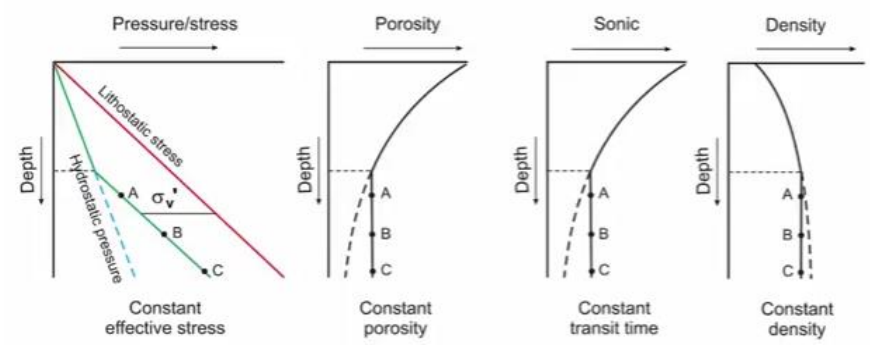

Gambar 4. Karakteristik data log shale terhadap mekanisme loading. Zona overpressure ditunjukkan oleh data porositas, sonik, dan densitas yang berubah menjadi konstan dari keadaan normal [7].

\section{Fluid expansion}

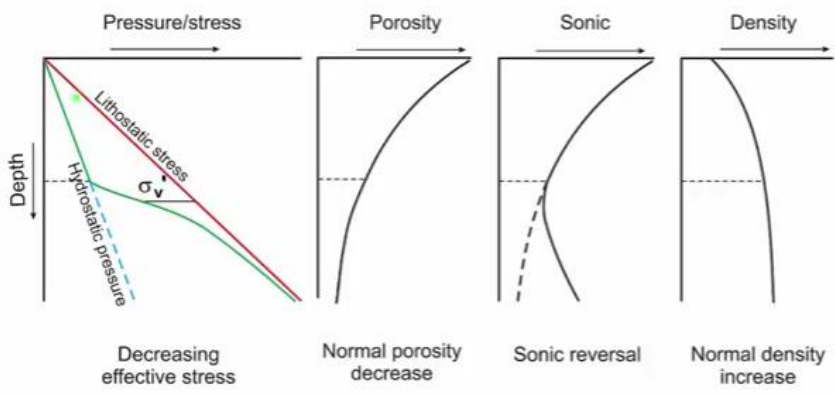

Gambar 5. Karakteristik data log shale terhadap mekanisme unloading. Zona overpressure ditunjukkan oleh data sonik yang mengalami kenaikan seiring bertambahnya kedalaman [8].

Berikut adalah hasil plot pada masing-masing data log shale terhadap kurva NCT pada sumur MZ:

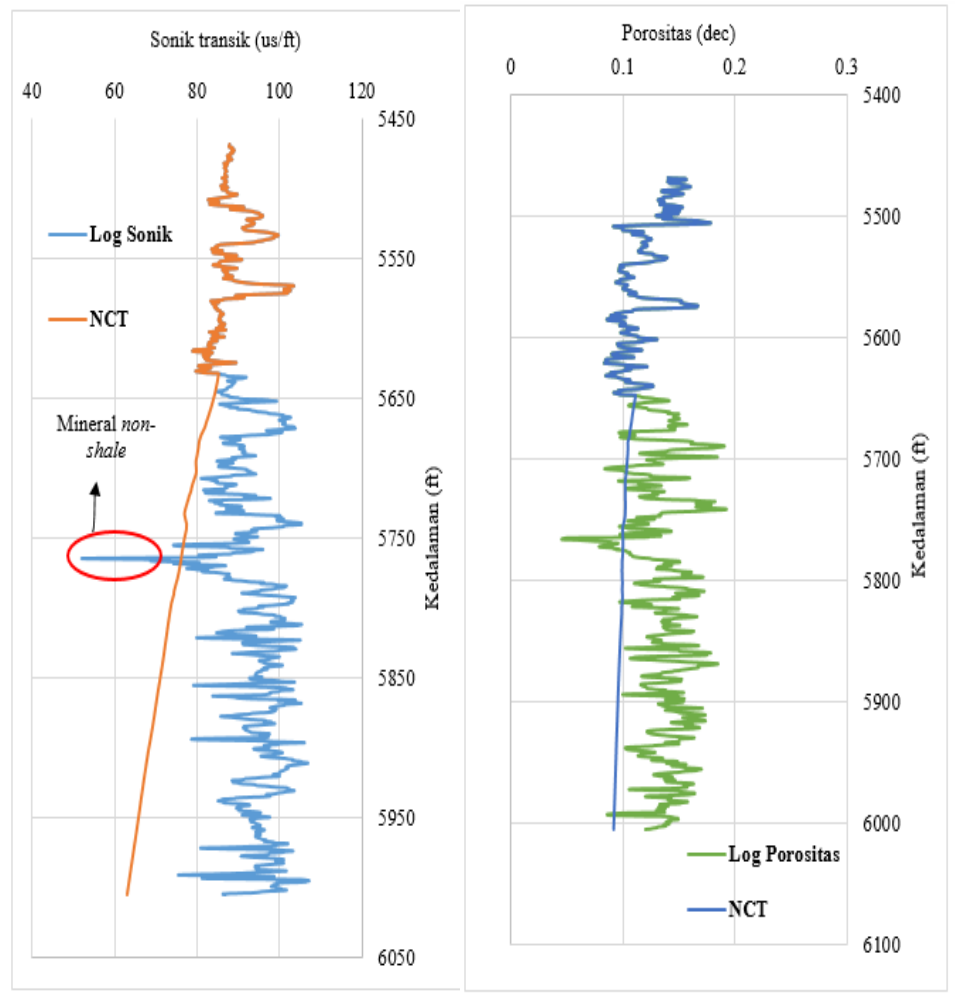




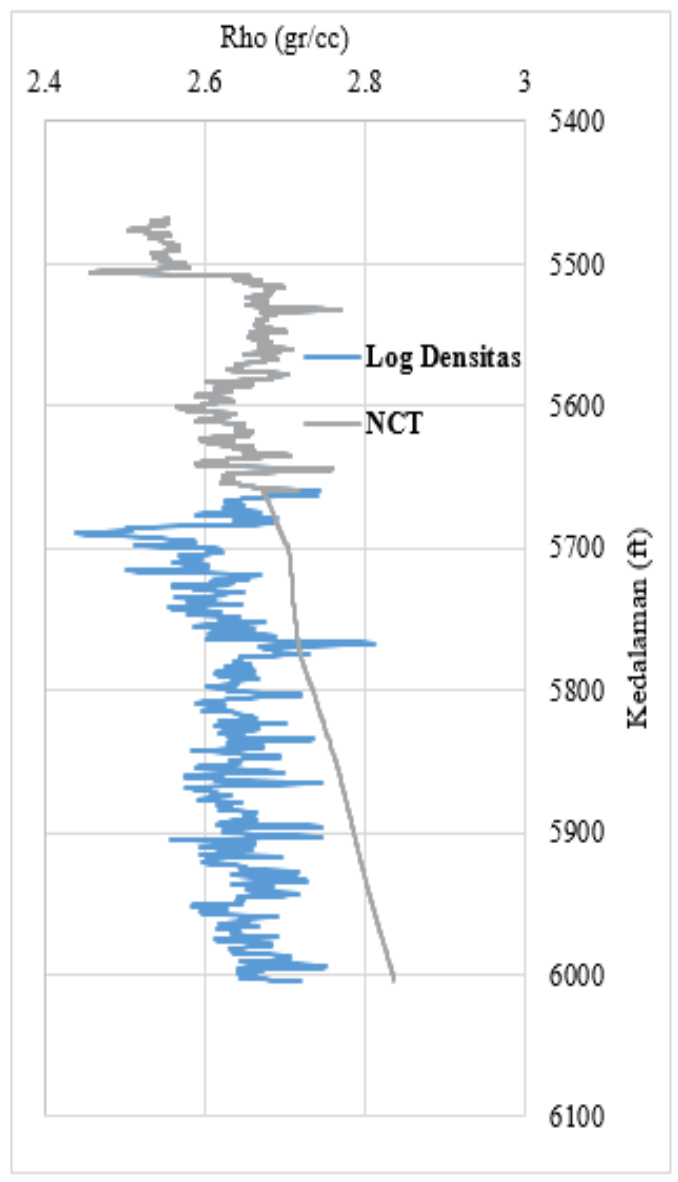

Gambar 6. Plot data log shale terhadap kurva NCT. Berdasarkan plot tersebut menunjukkan bahwa pada kedalaman $5641 \mathrm{ft}$ hingga $6000 \mathrm{ft}$ masingmasing data $\log$ mengalami perubahan konstan sehingga menunjukkan bahwa overpressure disebabkan oleh mekanisme loading.

Mekanisme loading dipengaruhi oleh laju pengendapan sedimen pada suatu formasi. Jika laju sedimentasi melebihi dari kondisi kesetimbangan, maka akan meningkatkan volume fluida yang harus dikeluarkan dari sistem pori batuan, sehingga jika volume fluida yang keluar dari sistem tidak seimbang dengan laju sedimentasi maka akan menghasilkan tekanan pori yang overpressure. Shale yang di plot pada gambar 6 terletak pada formasi Ngrayong. Berdasarkan referensi sebelumnya, formasi Ngrayong memiliki laju sedimentasi yang tinggi (rapid sedimentation), sehingga hal tersebut yang menyebabkan overpressure pada Lapangan MZ disebabkan oleh mekanisme loading.

\section{B. Hasil Perhitungan Tekanan Pori di Reservoir Karbonat}

Berdasarkan hasil perhitungan kompresibilitas bulk dan pori menggunakan metode FRM, diketahui bahwa nilai kompresibilitas bulk yaitu sebesar $1,4 \times 10^{-7}-2,3 \times 10^{-7}$ dan nilai kompresibilitas pori yaitu $5,9 \times 10^{-7}-8,1 \times 10^{-7}$. Lalu kedua parameter tersebut dimasukkan pada persamaan kompresibilitas dan menghasilkan profil tekanan pori di reservoir karbonat pada sumur MZ yaitu sebagai berikut :

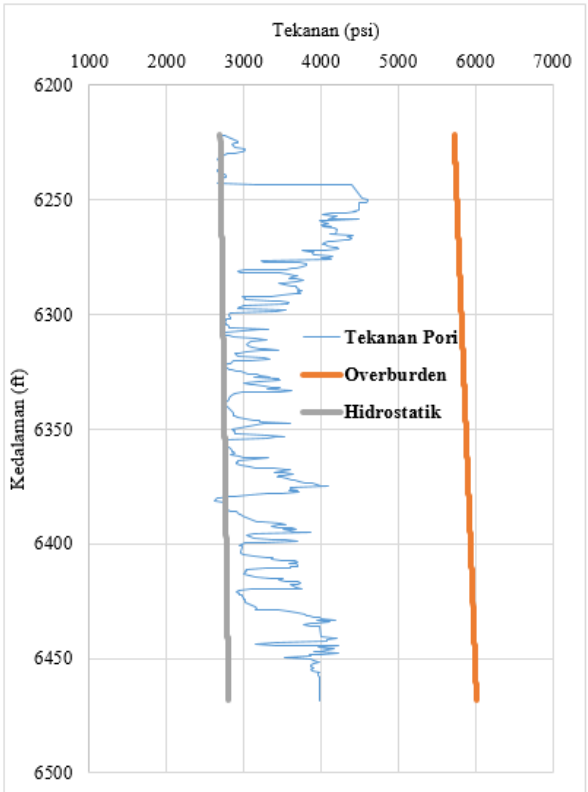

Gambar 7. Profil hasil perhitungan tekanan pori menggunakan metode kompresibilitas. Pada awalnya, tekanan pori bersifat normal hidrostatik namun mulai kedalaman $6245 \mathrm{ft}$, tekanan pori menjadi tekanan overpressure karena nilainya melebihi tekanan hidrostatik.

\section{Analisa Hasil Perhitungan Tekanan Pori}

Analisa hasil perhitungan tekanan pori di reservoir karbonat menggunakan metode kompresibilitas dilakukan dengan membandingkan hasil perhitungan tersebut dengan tekanan lumpur, d'Exponent, permasalahan pemboran, serta data tekanan langsung.

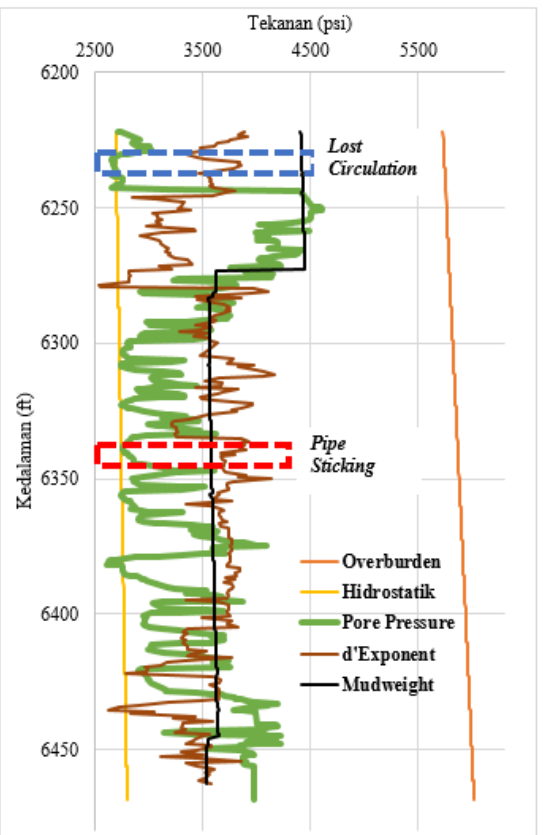

Gambar 8. Perbandingan antara hasil perhitungan tekanan pori dengan tekanan lumpur, d'Exponent, dan permasalahan pemboran. Terdapat kecocokan antara permasalahan pemboran yaitu lost circulation dengan tekanan pori, dimana salah satu penyebab dari permasalahan tersebut adalah tekanan lumpur yang lebih tinggi daripada tekanan pori. 
Selain itu, perbandingan antara hasil perhitungan tekanan pori dengan tekanan langsung yaitu :

Tabel 1.

Perbandingan antara hasil perhitungan tekanan pori dengan data tekanan langsung pada sumur MZ

\begin{tabular}{ccc}
\hline \hline Kedalaman (ft) & $\begin{array}{c}\text { Hasil Perhitungan } \\
\text { Tekanan Pori (psi) }\end{array}$ & $\begin{array}{c}\text { Data tekanan } \\
\text { langsung (psi) }\end{array}$ \\
\hline 6289 & 3721.472 & 3601.29 \\
6395 & 3500.73 & 3351.92 \\
6440 & 4001.08 & 3782.18 \\
\hline \hline
\end{tabular}

\section{Rekomendasi Berat Jenis Lumpur Pemboran}

Rekomendasi berat jenis lumpur pemboran menggunakan tekanan rekah sebagai batas maksimum dan nilai tekanan pori sebagai batas minimum. Selain itu juga menggunakan safety window pada tren perubahan data setiap kedalaman serta menggunakan safety factor sebesar $0.7 \mathrm{ppg}$.

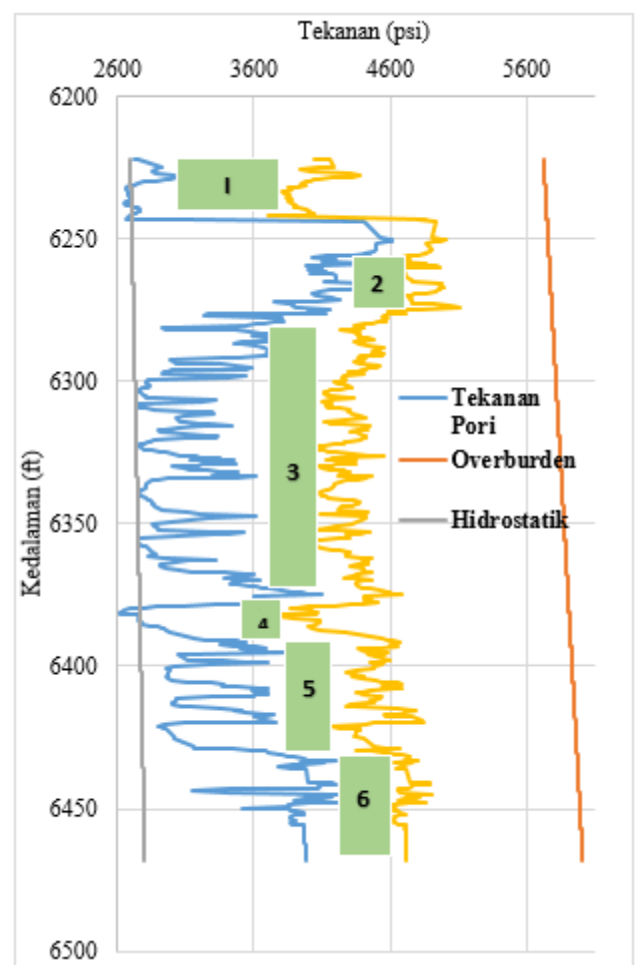

Gambar 9. Profil rekomendasi berat jenis lumpur pemboran pada sumur MZ. Terdapat 6 safety window yang bergantung pada perubahan nilai tekanan pori dan tekanan rekah. Rekomendasi berat jenis lumpur pemboran ditentukan dengan memberikan nilai minimal yang berkisar mulai $10-14.8$ ppg dan nilai maksimal yang berkisar antara $10.7-15.5 \mathrm{ppg}$.

\section{KESIMPULAN/RINGKASAN}

Berdasarkan penelitian yang telah dilakukan maka dapat disimpulkan bahwa :

1). Overpressure yang terjadi di Lapangan $M Z$ terjadi karena mekanisme loading atau disequilibrium compaction akibat laju sedimentasi yang tinggi (rapid sedimentation).

2). Nilai kompresibilitas bulk dan pori yang didapatkan melalui proses fluid replacement modelling pada sumur MZ yaitu bernilai $5,9 \times 10^{-7}-8,1 \times 10^{-7}$ untuk kompresibilitas pori dan $1,4 \times 10^{-7}-2,3 \times 10^{-7}$ untuk kompresibilitas bulk. 3). Tekanan pori di reservoir karbonat dapat di prediksi dengan baik menggunakan metode kompresibilitas. Hal tersebut ditunjukkan melalui kecocokan antara hasil perhitungan tekanan pori dengan tekanan lumpur, d'exponent, dan permasalahan pemboran. Selain itu, selisih antara hasil perhitungan tekanan pori menggunakan metode kompresibilitas dengan data tekanan langsung (RFT) juga cukup baik (kurang dari 500 psi) yaitu sebesar 162.63 psi.

4). Rekomendasi berat jenis lumpur pemboran untuk Lapangan MZ ditentukan dengan menggunakan safety factor sebesar $0.7 \mathrm{ppg}$ dan safety window yang berada di antara nilai tekanan pori dan tekanan rekah.

\section{DAFTAR PUSTAKA}

[1] R. O’Connor, S., Swarbrick, R. \& Lahann, “Geologically-driven Pore Fluid Pressure Models and Their Implications for Petroleum Exploration," 2011.

[2] A. Huffman, "The Future of Pressure Prediction using Geophysical Methods. Pressure Regimens in Sedimentary Basins and Their Prediction : AAPG," vol. 76, pp. 217-233, 2002.

[3] R. Wang, Z. \& Wang, "Pore Pressure Prediction Using Geophysical Methods in Carbonate Reservoirs: Current Status, Challenges, and Way Ahead," J. Nat. Gas Sci. Eng., 2015.

[4] M. R. Azadpour, M., Manaman, N. S., Ilkhchi, A. K. \& Sedghipour, "Pore Pressure Prediction and Modelling Using WellLogging Data in One of The Gas Fields in South of Iran," J. Pet. Sci. Eng. Elsevier, 2015.

[5] M. Atashbari, V. \& Tingay, "Compressibility Method for Pore Pressure Prediction,” Soc. Pet. Eng., 2012.

[6] A. Mouchet, P. \& Mitchell, Abnormal Pressures While Drilling. Perancis: Technip, 1989.

[7] A. M. Ramdhan, Overpressure in Indonesia's Sedimentary Basins. Bandung, 2017. 